\title{
Inefficiency Factors in Basic Health Care Supply in Côte d'Ivoire: A Comparative Econometric Analysis
}

\author{
Alliou S. Diarrassouba ${ }^{1}$ \\ ${ }^{1}$ Department of Economics, Faculty of Economics and management, Jean Lorougnon Guédé University, Daloa, \\ Côte d'Ivoire \\ Correspondence: Alliou S. Diarrassouba, Department of Economics, Faculty of Economics and Management, BP \\ 150 UFRSEG UJLOG, Jean Lorougnon Guédé University, Daloa, Côte d'Ivoire. Tel: 225-070-822-7274. E-mail: \\ diassa2000@hotmal.com
}

Received: February 27, 2021

Accepted: March 30, 2021

Online Published: May 15, 2021

doi:10.5539/ijef.v13n6p46

URL: https://doi.org/10.5539/ijef.v13n6p46

\begin{abstract}
The achievement of universal health coverage has put Primary Health Care back at the center of policy orientations, particularly by identifying factors likely to improve the organization of peripheral facilities. However, this objective depends on the econometric methods used, especially for cross-sectional data and small sample sizes.

This study aims to examine the sensitivity of the most usual estimation methods (Stochastic Frontier Analysis (SFA), Data Envelopment Analysis (DEA), DEA double bootstrap, Tobit, Truncated Standard Regression) for evaluating the scores and determinants of technical inefficiency of Primary Health Care Facilities (PHCF) in Côte d'Ivoire. Estimates show average technical efficiency scores of $94.13 \%$ for the DEA versus $89.61 \%$ for the SFA and $82.24 \%$ for the DEA double bootstrap. The results also indicate a proportion of determinants of technical inefficiency, in decreasing order of importance, with the DEA double bootstrap, the SFA, truncated regression and Tobit. This technical inefficiency can be improved in policies to promote basic health care by: increasing the proportion of nurses in the medical staff, the nurse/inhabitant ratio, the adult literacy rate by region, controlling the average capacity of the PHCFs, improving their geographical accessibility and reducing the rate of extreme poverty by health region.
\end{abstract}

Keywords: DEA double bootstrap, inefficiency, truncated regression, Primary Health Care, Stochastic frontier analysis, Tobit

JEL Classification: C13, C14, C31, C34, I12, I18.

\section{Introduction}

Debates on the issues of health costs, budget deficits, the medium and long-term sustainability of healthcare supply structures or organizations in charge of health insurance remain recurrent in developed countries and even more so in developing countries. According to the United Nations Development Program (UNDP, 2016), universal access to basic health services can be a very important lever for reducing extreme poverty and accelerating social inclusion, particularly in developing countries. For the World Health Organization (WHO report, Universal Health Coverage, 2018), the need to put primary health care (PHC) back at the center of efforts is a fundamental aspect of universal health coverage in order to achieve, among other things, sustainable development objectives related to health. One of the essential keys would be the enhancement of peripheral health structures and community systems in order to induce an improvement in resilience. Otherwise, failure to reverse the current trend would lead to the exclusion of approximately five billion people from access to health care in 2030 (WHO, 2019).

Thus, these debates are part of the general question concerning the control and optimality of public health expenditure with a view to improving the well-being of populations (WHO, 2018; Ouertani et al., 2018; Katharakis et al., 2014; Sen, 1983; and Becker, 1962). But even more so, knowledge and prioritization of the levers through which the use of these resources could be improved remain fundamental and constitute a major challenge, especially in Sub-Saharan African countries (Ouertani et al., 2018; Lawanson \& Novignon, 2017; Dukhan, 2010). 
However, an overview of studies on this issue reveals that the vast majority of them have focused more on the determinants of inefficiency than on the method of estimating efficiency per se (Lawanson \& Novignon, 2017; Dukhan, 2010; Ouellette \& Petit, 2010). Yet, there are two problems with such an approach.

On the one hand, the factors explaining the level of inefficiency in the second stage remain largely linked to the results of the level of efficiency obtained in the first stage (failure to correct interdependencies between variables). These discrepancies may be linked to the choice of variables and the data in the study, but also depend heavily on the inadequacies of the estimation method, whether parametric or non-parametric (Lawanson \& Novignon, 2017; Katharakis et al., 2014; Simar \& Wilson, 2007). Generally, in practice, Data Envelopment Analysis (DEA) methods, the main non-parametric approach adopted, are preferred to Stochastic Frontier Analysis (SFA) methods, the dominant parametric approach, in health sector performance studies (See Ouellette and Petit (2010) through a review of the studies carried out on the issue).

On the other hand, the robustness of methods for estimating explanatory factors may be marred by the problem of inconsistent inference of confidence intervals (serial correlation between the error term and efficiency scores). Generally, in the case of two-stage DEA models, Tobit is chosen for technical post-efficiency estimation (Mujasi, 2016). This approach remains limited according to some authors who use truncated regression (Anang et al., 2020; Tiéhi, 2020; Pérez-Cárceles et al., 2018; Tchaumann, 2015) to account for the truncated and uncensored nature of the data. Thus, the DEA double bootstrap of Simar and Wilson (2007) is used to correct the shortcomings of previous approaches (Anang et al., 2020; Olivares et al., 2020; Diarrassouba, 2018; Pérez-Cárceles et al., 2018). This method, like the SFA, internalizes efficiency scores, which are regressed to determine explanatory factors. For both models, the results of the scores and explanatory factors are thus obtained simultaneously and not sequentially. But in addition, the DEA double bootstrap can externalize the scores, correcting biases linked to the possible correlation between the variables and the inconsistency of the confidence intervals.

According to Varabyova and Schreyögg (2013), sensitivity analysis in inefficiency studies takes two forms: internal sensitivity and external sensitivity. In the present study, sensitivity is assessed in its external dimension. The validity of this sensitivity is tested either by the invariability of the results over time or by comparing the efficiency scores estimated by DEA and estimated by SFA using the same set of input and output variables. It then involves the comparison of the DEA and SFA scores with the same set of input and output variables and the comparison of the Tobit, standard truncated regression and DEA double bootstrap models.

This study is based on Farell's (1957) conception of technical efficiency, which is based on a production function reflecting the relationship between combinations of inputs in order to obtain outputs. In other words, a health entity is technically efficient when it produces as many health outputs as possible with a given level of health inputs, or if it produces a given level of health output with the minimum possible level of health inputs.

In Côte d'Ivoire, PHC is the basis for the organization of the health care system (National Health Development Program, PNDS, 2016-2020). The provision of this care is provided by first contact health facilities, which make up the vast majority of the overall healthcare offer. They account for $93 \%$ of the total healthcare supply infrastructure according to the Ministry of Health and Public Hygiene (2019). The State's policy to guarantee "access to healthcare for all" through universal health coverage is essentially based on these health facilities. To this end, the State has launched the construction and/or rehabilitation of approximately 200 facilities in this category between 2016 and 2020 (PNDS, 2016-2020).

Despite an abundant literature on the issue, comparative evaluations of methods for estimating the factors of inefficiency in health care systems in Africa, particularly in Côte d'Ivoire, are recent. Therefore, this study aims to contribute to informing the political decision on the levers and obstacles to be analyzed in order to improve the efficiency of the use of resources allocated to primary health care institutions in Côte d'Ivoire by implementing the sensitivity of econometric methods.

The objective of this study is to examine the sensitivity of the most usual estimation methods (SFA, DEA, DEA double bootstrap, Tobit, Standard Truncated Regression) for evaluating the scores and determinants of the technical efficiency of primary health care facilities (PHCFs) in Côte d'Ivoire. Specifically, the aim is to (i) test the sensitivity of the technical efficiency level of PHCFs to the SFA, DEA and double bootstrap DEA estimation methods; (ii) measure how sensitive the factors explaining the estimated inefficiency levels are to the main methods used in the literature. To do so, the following assumptions are made: (i) overall, PHCFs are technically inefficient with variable scores depending on the estimation method used and (ii) exogenous and endogenous variables significantly, positively and variably influence the inefficiency of PHCFs depending on the method used. 
This study is organized into four points. Section 1 provides an overview of the literature review of the methods used. Section 2 discusses the methodology through a description of the data, the variables, and the specification of the estimation models used. Section 3 analyzes the SFA, DEA and DEA double bootstrap results of the efficiency scores and determinants of the technical inefficiency found.

\section{Strengths and Weaknesses of the Main Econometric Methods in the Literature}

The most popular methods are the SFA for parametric approaches and the DEA for non-parametric approaches to which Tobit, standard truncated regression and DEA double bootstrap for the second stage are generally associated. This section presents a summary of the advantages and disadvantages between the DEA and SFA methods on the one hand, and between the Tobit, standard truncated regression and DEA double bootstrap models on the other hand.

\subsection{DEA and SFA Comparison}

In general, for Jacobs et al. (2006) and Leleu and Derveaux (1997), estimates made with the DEA approach are considered sensitive to the specification of the production function (choice and number of variables), the sample size and the presence of outliers. As for the SFA method, it remains dependent on the definition of the appropriate functional form of the technology and on its poor adaptability to multi-output models that are nevertheless recurrent in health (Dukhan, 2010). The choice of a method is linked to the specificities of each method (Table 1) and to the objectives sought.

Table 1. Overview of the differences between DEA and SFA

\begin{tabular}{|c|c|c|}
\hline & DEA & SFA \\
\hline 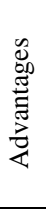 & $\begin{array}{l}\text {-No specification on the functional form of the adopted technology } \\
\text {-Estimating efficiency in a multi-output as well as single-output } \\
\text { settings } \\
\text { - Two-stage regression for factors explaining inefficiency with the } \\
\text { possibility of correcting colinearity problems }\end{array}$ & $\begin{array}{l}\text {-Distinction of the random error from the error related to } \\
\text { efficiency variation of the studied entity. } \\
\text {-Reduced inefficiencies may have statistical properties } \\
\text {-Not very sensitive to outliers }\end{array}$ \\
\hline . & $\begin{array}{l}\text {-Sensitive to outliers: Large errors in measurement and/or } \\
\text { variables can affect measures of inefficiency. } \\
\text {-Reduced inefficiencies have no statistical properties. } \\
\text {-Relative measure of efficiency by comparison of all other units to } \\
\text { the reference taken as "best practice": risk of over- or } \\
\text { underestimation related to the characteristics of the reference. }\end{array}$ & $\begin{array}{l}\text {-Sensitive to sample size: risk of misspecification due to } \\
\text { small sample size } \\
\text {-Need to represent the technology by a particular parametric } \\
\text { form } \\
\text { - Moderately suitable for multi-outputs } \\
\text {-Simultaneous regression (first stage) for the variables } \\
\text { explaining inefficiency: risk of colinearity between outputs } \\
\text { and inputs on the one hand and the environment variables } \\
\text { the other hand integrated in the production function. }\end{array}$ \\
\hline
\end{tabular}

Source: Adapted from Dukhan (2010), Jacobs et al. (2006) and Chaffai (1997).

\subsection{Comparison of Tobit, Truncated Regression and DEA Double Bootstrap}

The factors explaining technical inefficiency are obtained by regression of the scores obtained in the first stage and the environment variables. The most recurrent models in the literature are: Tobit, truncated regression and DEA double bootstrap for models associated with DEA (Tchaumann, 2015). The SFA method systematically gives the explanatory factors.

Table 2. Overview of the differences between Tobit, truncated regression and DEA double bootstrap

\begin{tabular}{|c|c|c|}
\hline & Advantages & Limitations \\
\hline \multirow{10}{*}{ : } & \multirow{10}{*}{$\begin{array}{l}\text { Adapted to the regression of efficiency scores } \\
\text { usually censored on the left side. }\end{array}$} & -Not appropriate when variables have truncation \\
\hline & & characteristics: this characteristic is common in DEA estimates \\
\hline & & of efficiency scores. \\
\hline & & -Risk of estimation error: high probability of bias in the scores \\
\hline & & due to the method used to determine them with the DEA \\
\hline & & Cincesto \\
\hline & & -Colinearity between variables of the first stage (inputs and \\
\hline & & outputs) and those of the second stage \\
\hline & & -Inconsistency of confidence intervals related to the likely \\
\hline & & correlation between the error term and efficiency scores. \\
\hline
\end{tabular}




\begin{tabular}{lll}
\hline & Solves the problem of truncated variables. & $\begin{array}{l}\text {-Risk of estimation error: high probability of bias in the scores } \\
\text { due to the method used to determine them with the DEA. } \\
\text {-Colinearity between variables of the first stage and those of } \\
\text { the second stage. }\end{array}$ \\
$\begin{array}{ll}\text {-Inconsistency of confidence intervals related to the likely } \\
\text { correlation between the error term and efficiency scores. }\end{array}$ \\
\hline $\begin{array}{l}\text {-Colves the problem of truncated variables. } \\
\text { inconsistency of confidence intervals. }\end{array}$
\end{tabular}

Source: Adapted from Tchaumann (2015) and Simar and Wilson (2007).

The choice of each of these models should take into account the possible advantages and limitations inherent to each one (Table 2), as well as the objectives sought.

\section{Methodology}

This section describes the data and variables and presents the specification of the study models.

\subsection{Data Source}

The data for this study come from three sources: the National Population Survey (2014), the Annual Health Situation Report (RASS, 2013) and the "Support to the primary health map" project in 2013. These are cross-sectional data.

The National Population Survey (2014) is conducted by the National Institute of Statistics (INS) in collaboration with the Ministry of Planning and Development. Its objective is to gain knowledge of the demographic, socio-economic and cultural characteristics of the population in order to take better account of population issues in the development, monitoring and evaluation of economic, social and cultural development policies, plans, programs and projects.

The RASS (2013) is carried out by the Ministry of Health and the Fight against AIDS (MSLS). Based on information from the National Health Information System (SNIS), the RASS collects data (financial, human and material resources and epidemiologic profile) produced by institutions at different levels of the health pyramid.

The project "Support to the primary health map" was carried out by the National Office of Technical and Development Studies (BNETD, 2013). It involves the inventory and mapping of the primary health infrastructures concerning the organization, the geographical location of the health infrastructures and the beneficiary population of these structures. It is a tool for regulating the healthcare service offer.

This study focuses on the care provided by the PHCFs, with the health regions as the DMU (Decision Making Unit). The PHCFs in each health region are aggregated and considered as a single decision making unit (DMU). The analysis of the results will therefore be done by health region.

\subsection{Description of Variables}

The sixteen variables consist of inputs (factors of health care delivery), outputs (health outcomes), and variables likely to influence the functioning of health facilities (constraints or levers).

\subsubsection{Inputs}

The inputs relate to the labor factor and the capital factor. In general, the labor factor is made up of medical staff in health studies (Lawanson \& Novignon, 2017). In this case it is composed of the number of: doctors (Med), nurses (Inf) and midwives (Sag_fem). For the capital factor, with respect to the available data, the number of observation beds is used as the proxy (Lawanson \& Novignon, 2017; Kiriga et al., 2013).

\subsubsection{Outputs}

In relation to the level of analysis in this study, i.e., PHCFs, the outputs are essentially referenced to maternal and child health indicators associated with medical consultations (Diarrasouba, 2018; Kiriga et al., 2013). This study selects five (5) output variables: (i) Medical consultations (Nb_consult); (ii) the Number of Births Attended by Skilled Personnel (Acc_Assist), considered as a proxy for health inequality, which makes it possible to assess health coverage (Kochou et al., 2014); (iii) the four (4) Prenatal Consultations (CPN4), considered by the WHO to be one of the best maternal health indicators (Kiriga et al., 2013); (iv) The Number of Children who received Vitamin A (Vit_A): Vitamin A is the key component of the package to combat weight insufficiency of 
children in Côte d'Ivoire as part of the fight against child malnutrition; (v) The number of children who received the BCG vaccine (Vac_BCG): Vaccination coverage remains one of the main child health indicators for WHO and UNICEF. In order to prevent the risk of tuberculosis infection, children are vaccinated with this vaccine as part of the package of vaccines designed for them. Among other things, it remains important in the prevention of HIV/TB co-infection.

\subsubsection{Environment Variables}

The factors explaining technical inefficiency in health studies are, in general, of two kinds: institutional (or governmental) and socioeconomic ((Lawanson and Novignon, 2017; Mujasi, 2016). This study identifies seven (7) explanatory variables: (i) geographic accessibility (Acc_Geo): the average distance, between 3 miles and 9 miles, separating the population from the nearest PHCF; (ii) the number of PHCFs per region ( $N b \_E S P C$ ); these two variables reflect the geographic influence on the level of performance of the PHCFs (Téhi, 2018: Combier et al, 2013); (iii) the Ratio (Hbt/Inf ) Nurse per inhabitant considered as a performance indicator reflecting the health development of countries (WHO and UNDP); (iv) the Proportion of Nurses (\% Nurse/persmed): reflects the density and specialization of the institution's primary care activity. It can be considered as a regulatory variable for the functioning of the PHCF; (v) Average size or capacity of the PHCF by region (Taille_moy): calculated as the ratio between the number of observation beds of the PHCF and the number of PHCF in the region. It can influence the level of efficiency of the institution through an increase in the activity rate per staff member but especially through an improvement in the conditions for receiving patients; (vi) the rate of extreme poverty per region (Taux_Extrempauvr), which reflects the situation of the national economy in terms of living standards and regional disparities (inequalities in development). This variable, relative to various studies, reveals that a high level of poverty is a source of inefficiency in the health system in the sense that a significant and positive correlation is established between the increase in gross national income per capita or GDP per capita and the efficiency of the health system (Combier et al, 2013; Afonso \& St. Aubyn, 2011); (vii) the adult literacy rate by region (Taux_Alphabet); according to various studies (Ouertani et al., 2018; Alvarez and Hernandez, 2009), it is significantly and positively correlated with the efficiency of maternal health care provision in sub-Saharan Africa

\subsection{Models specification}

The estimations in this study are based on the models: SFA, DEA, Tobit, truncated regression and DEA Double bootstrap.

\subsubsection{SFA versus DEA}

\section{SFA Model}

The Stochastic Frontier Analysis (SFA) method was developed by Aigner, Lovell and Schmidt (1977), Battese and Corra (1977) and by Meeusen and Van den Broeck (1977). With reference to the framework of Lawanson and Novignon (2017) and Katharakis et al (2014), in this study, SFA estimations are carried out in multi-outputs through a Cobb-Douglas type functional form production function as a technology. Thus, the basic econometric model of this study can be written as follows:

$$
Y i=\beta X i+(V i-U i), i=1, \ldots 19
$$

With

$Y i$ : A k x 1 vector, represents the logarithm of the production or output quantities of the PHCFs of the i-th health region;

$X i$ : A k x 1 vector, represents the logarithm of the input quantities used by the PHCFs of the $\mathrm{i}$-th health region;

$\beta$ : The parameter vector of the technology to be estimated;

$v_{j}$ : Random errors that represent random variables (measurement error, random factors); they are assumed to be normally, independently and identically distributed;

$u_{j}$ : Errors in non-negative random variables that are assumed to represent technical inefficiency in production and assumed to be normally, independently and identically distributed and truncated.

This equation can be rewritten as follows:

$$
\begin{aligned}
& \operatorname{Ln}(\text { Outputi })=\beta 0+\beta 1 \operatorname{Ln}(\text { Medi })+\beta 2 \operatorname{Ln}(\text { Infi })+\beta 3 \operatorname{Ln}\left(\text { Sag }_{\text {Femi }}\right)+\beta 4 \operatorname{Ln}(\operatorname{Litsi})+(V i-U i), i=1, \ldots 19 \\
& \text { With Output }=\left(N_{-} b_{-} \text {consult }, A_{c c}{ }_{-} \text {Assist, } C P N 4, V i t_{-} A, V a c_{-} B C G\right) \text { of the } i \text { health region }
\end{aligned}
$$

In the SFA model, in the second stage, a regression of the environment variables that influence the technical 
inefficiency of the PHCFs in each health region, represented by the error term $U i$, is used to obtain the explanatory factors. These variables are evaluated, with reference to the framework of Katharakis et al. (2014) as follows:

$$
U i=\theta i Z i+W i
$$

With

$Z i$ : represents the environment variables that may influence the operation of the PHCFs in the i-th health region;

$\theta i$ : the parameter vector to be estimated to obtain the coefficients of the explanatory variables;

$W i$ : the usual error term

The model can be rewritten as follows:

\section{DEA Model}

$$
\begin{gathered}
U i=\theta 0+\theta 1 \mathrm{Nb} \_ \text {ESPC } i+\theta 2 \text { Taille_moy } i+\theta 3 \mathrm{Hbt} / \operatorname{Inf} i+\theta 4 \mathrm{Inf} / \text { persmed } i+ \\
\theta 5 \text { Acc_Geo } i+\theta 6 \text { Taux_Alphabet } i+\theta 7 \text { Taux_Extrempauvr } i+W i
\end{gathered}
$$

Compared to the SFA model, the DEA model estimates the efficiency scores and externalizes them in order to estimate the factors explaining inefficiency through a Tobit or other chosen model except for the case of the DEA double bootstrap. The basic theoretical model for the estimation of technical efficiency scores by DEA is used in this input-oriented study (Diarrassouba, 2018 and Mujasi, 2016), under the assumption of variable returns to scale. The equation consists in, given an input level and an output level, solving $\mathrm{K}$ linear programs from each health region as follows:

$$
\left\{\begin{array}{l}
T E_{I}(x, y)=\theta(x, y)=\min \{\theta / \theta \succ 0 ;\} \\
y_{i} \leq \sum_{i=1}^{n} \lambda_{i} y_{i} \\
x_{i} \geq \sum_{i=1}^{n} \lambda_{i} x_{i} \\
\sum_{i=1}^{n} \lambda_{i}=1 \\
\lambda_{i} \geq 0 ; i=1, \ldots n
\end{array}\right.
$$

With $x$ the inputs vector, $y$ the outputs vector for each health region $i, i=1, \ldots 19$ and $\lambda_{i}$ an optimization parameter.

\subsubsection{Tobit, Truncated Regression and DEA Double Bootstrap Models}

In a DEA model, the explanatory factors of technical inefficiency are obtained through either a Tobit, a truncated regression or a DEA double bootstrap model.

\section{Tobit versus truncated regression}

The mathematical formalization of the Tobit model and the standard truncated model are similar. The difference between the two models is based solely on the nature of the variables, depending on whether they are censored or truncated (Tchaumann, 2015).

The equation is as follows:

$$
\hat{\theta}_{i}=z_{i} \beta+\varepsilon_{i} ; \quad i=1, \ldots n
$$

With

$\ddot{\theta}_{i}$ : The technical efficiency score of each health region's PHCF obtained with the DEA;

$z_{i}$ : The vector of factors likely to affect the technical efficiency of the health region;

$i ; \beta$ the parameter vector and is the identically and independently distributed error term.

The model is deduced:

$$
\begin{aligned}
\hat{\theta} i= & \beta 0+\beta 1 \mathrm{Nb} \_\mathrm{ESPC} i+\beta 2 \text { Taille_moy } i+\beta 3 \mathrm{Hbt} / \mathrm{Inf} i+\beta 4 \mathrm{Inf} / \mathrm{persmed} i+ \\
& \beta 5 \text { Acc_Geo } i+\beta 6 \text { Taux_Alphabet } i+\beta 7 \text { Taux_Extrempauvr } i+\varepsilon i
\end{aligned}
$$

DEA Double bootstrap or Algorithm \# 2 by Simar and Wilson (2007) 
Unlike Tobit and truncated regression, DEA double bootstrap does not require the outsourcing of DEA efficiency scores. It consists of a double re-sampling of the original data with looping following the DEA estimation with a double objective: to obtain robust technical efficiency scores and reliable determinants of these scores (Simar and Wilson, 2007). Formally, its resolution focuses on the following main stages:

i. Based on the initial sample, we estimate technical efficiency scores under input-oriented DEAs: $\hat{\theta} i(i=1 \ldots n)$ ii. The estimators $\hat{\beta}$ are obtained from a truncated regression $0<\hat{\theta}_{i}-\beta z_{i}+\varepsilon_{i} \leq 1$, using $m<n$ observations with $\hat{\theta}_{i} \prec 1, \hat{\theta}_{i}$ is the technical efficiency score of the $i$ health region's PHCFs estimated under DEA, $\varepsilon_{i}$ is normally distributed with a left truncation at $-z_{i} \hat{\beta}$ and a right truncation at $1-z_{i} \hat{\beta}, z_{i}$ is the vector of environment variables that affect the efficiency of the health region, and $\beta$ is the vector of the parameters to be estimated.

iii. In successive iterations (in four stages) $L_{1}=500$ times, a sample of bootstrap estimators is obtained, $B i=\left\{\hat{\theta}_{i b}^{*}\right\}_{b=1}^{L_{1}} ; i=1, \ldots n$. This is done as follows:

a. For each $i=1 \ldots n, \varepsilon_{i}$ is extracted from the law $N\left(0 ; \hat{\sigma}^{2}\right)$ left-truncated at $-z_{i} \hat{\beta}$ and right-truncated at $1-z_{i} \hat{\beta}$

b. Then the following estimator is calculated $\theta_{i}^{*}$ such as $\theta_{i}^{*}=z_{i} \hat{\beta}+\varepsilon_{i} ; i=1, \ldots n$.

c. Then a pseudo sample is built $\left(x_{i}^{*} ; y_{i}^{*}\right)$, with $x_{i}^{*}=x_{i}$ and $y_{i}^{*}=y_{i} \hat{\theta}_{i} / \theta_{i}^{*}$

d. The new DEA estimator or bootstrap estimator $\hat{\theta}_{i}^{*} ; i=1, \ldots n$ is calculated from the pseudo sample created $\left(x_{i}^{*} ; y_{i}^{*}\right)$; in other words, the variables $X$ and $Y$ are respectively replaced by $Y^{*}=\left\{y_{i}^{*} i=1 \ldots \ldots \ldots \ldots n\right.$ and $X^{*}=\left\{x_{i}^{*} i=1 \ldots \ldots \ldots \ldots n\right\}$ in the initial program.

iv. For each health region $i=1, \ldots n$ the unbiased estimator $\hat{\hat{\theta}}_{i}(i=1 \ldots n)$ is calculated using bootstrap estimators obtained from $B_{i}$ and the initial estimators $\hat{\theta}_{i}$.

v. We estimate a truncated regression of $\hat{\hat{\theta}}_{i}(i=1 \ldots n)$ on $z_{i}(i=1 \ldots n)$ to obtain the estimators $\hat{\hat{\beta}}$.

vi. By successive iterations (in three stages) $L_{2}=2500$ times, a sample of bootstrap estimators is obtained, $\Delta=\left\{\hat{\hat{\beta}}_{i b}^{*}\right\}_{b=1}^{L_{2}} ; i=1, \ldots n$. This is done as follows:

a. For each $i=1 \ldots n, \varepsilon_{i}$ is extracted from the $N\left(0 ; \hat{\sigma}^{2}\right)$ law, left-truncated at $-z_{i} \hat{\hat{\beta}}$ and right-truncated at $1-z_{i} \hat{\hat{\beta}}$

b. Then the following estimator is calculated $\theta_{i}^{* *}$ such as $\theta_{i}^{* *}=z_{i} \hat{\hat{\beta}}+\varepsilon_{i} ; i=1, \ldots n$.

c. We estimate a truncated regression, by maximum likelihood, of $\theta_{i}^{* *}$ over $z_{i}$ to obtain the estimators $\hat{\hat{\beta}}^{*}$.

vii. Finally, we use the bootstrap estimators of $\Delta$ and the initial estimators $\hat{\hat{\beta}}$ to build the confidence intervals of each element $\beta$. The confidence interval for any $\beta_{j}$ is constructed by finding the values $a_{\alpha / 2}$ and $b_{\alpha / 2}$ so that:

$$
P_{r o b}\left(-b^{*} \alpha / 2 \leq \hat{\hat{\beta}}_{j}^{*}-\hat{\hat{\beta}}_{j} \leq-a^{*} \alpha / 2\right) \approx 1-\alpha
$$

This gives an estimated confidence interval of: $\left[\hat{\hat{\beta}}_{j}+a^{*} \alpha / 2, \hat{\hat{\beta}}_{j}+b^{*} \alpha / 2\right]$

It should be noted that the bias in the double bootstrap model of Simar and Wilson (2007) is non-positive and is obtained as follows:

$$
\hat{\theta} i=\hat{\theta} i-\operatorname{bias}(\hat{\theta} i) \text { with } \operatorname{Bias}(\hat{\theta} i)=\left(\frac{1}{L 1} \sum_{b=1}^{L 1} \hat{\theta} i b^{*}\right)-\hat{\theta} i
$$




\section{Results and Discussion}

This section analyzes the results of the sensitivity of the scores and the factors of technical inefficiency in the provision of basic health care in Côte d'Ivoire to the econometric methods used. This analysis is preceded by descriptive statistics that provide an overview of the characteristics of the study variable.

\subsection{Descriptive Statistics}

The variables in this study (Table 3) have a number of salient features that provide a better understanding of the conceptual framework.

Table 3. Descriptive statistics of the variables

\begin{tabular}{|c|c|c|c|c|c|c|}
\hline & Variables & Mean & Std.Dev. & Median & Min & Max \\
\hline \multirow{4}{*}{$\begin{array}{l}\stackrel{\tilde{\Xi}}{\Xi} \\
\text { }\end{array}$} & Med & 32.316 & 64.744 & 17 & 1 & 295 \\
\hline & Inf & 110.84 & 61.04 & 103 & 33 & 313 \\
\hline & Sag_Fem & 61.737 & 61.828 & 48 & 16 & 301 \\
\hline & Lits & 346.42 & 133.91 & 331 & 117 & 593 \\
\hline \multirow{5}{*}{ 芯 } & $\mathrm{Nb}$ _consult & $3.0 \mathrm{e}+05$ & $2.8 \mathrm{e}+05$ & $2.4 \mathrm{e}+05$ & 78772 & $1.4 \mathrm{e}+06$ \\
\hline & Acc_Assist & 21583 & 21543 & 15964 & 6867 & $1.1 \mathrm{e}+05$ \\
\hline & CPN4 & 14648 & 20090 & 11195 & 2717 & 95410 \\
\hline & Vit_A & 9785.1 & 12218 & 6719 & 884 & 56598 \\
\hline & Vac_BCG & 40628 & 33971 & 32335 & 13607 & $1.7 \mathrm{e}+05$ \\
\hline \multirow{7}{*}{ 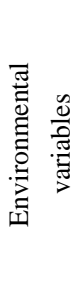 } & Nb_ESPC & 102.37 & 38.504 & 91 & 44 & 185 \\
\hline & Taille_moy & 3.413 & 0,64056 & 3.3333 & 1.5395 & 4.24 \\
\hline & Hbt/Inf__ & 10946 & 2768 & 10884 & 7165.9 & 16853 \\
\hline & $\%$ Inf/persmed & 59.474 & 7.7915 & 60 & 34 & 72 \\
\hline & Acc_Geo & 25.658 & 9.1501 & 26 & 8.5 & 48 \\
\hline & Taux_Alphabet & 36.321 & 11.519 & 38 & 19 & 59.6 \\
\hline & Taux_Extrempauvr & 8.5579 & 3.0518 & 8.5 & 3.4 & 14.9 \\
\hline
\end{tabular}

Source. Author.

From Table 1, with regard to inputs, we note a predominance of paramedical staff (nurses and midwives) over medical staff; an average of 111 nurses and 62 midwives against an average of 33 doctors. This finding confirms the nature of the DMU in this study (the PHCFs) and is confirmed by the proportion of nurses in the medical staff (60\% on average).

Thus, the analysis reveals instability in the distribution of inputs and outputs as opposed to that of variables in a relatively stable environment. In other words, the spread of distributions is relatively large between the mean and the median with inputs and outputs compared to the environment variables (Diarrassouba, 2018).

In addition, it is observed that on average $8.6 \%$ of the population in the study sample is extremely poor compared to a national average rate of $10 \%$ (National Population Survey, 2014). In the opposite direction, these statistics indicate an average adult literacy rate of $36.3 \%$ against a national average of $44 \%$. The analysis also indicates that, on average, $25.7 \%$ of the population is located between 3 miles and 9 miles from a health center.

\subsection{Technical Efficiency Scores: SFA, DEA and DEA Double Bootstrap Sensitivity}

The results of the technical efficiency scores for the three models are presented and discussed in a general framework and by health region (Table 4).

Table 4. Characteristics of SFA, initial DEA and bias-corrected DEA scores

\begin{tabular}{cccccccc}
\hline & $\begin{array}{c}\text { SFA } \\
(\hat{\theta})\end{array}$ & $\begin{array}{c}\text { DEA_VRS } \\
(\hat{\theta})\end{array}$ & $\begin{array}{c}\text { DEA } \hat{\hat{\theta}} \\
\text { (double bootstrap) }\end{array}$ & $\begin{array}{c}\text { Variation } \\
\text { DEA_VRS }\end{array}$ & $\begin{array}{l}\text { Variation DEA_VRS } \\
-\end{array}$ & $\begin{array}{l}\text { Variation } \\
\text { double bootstrap } \\
\text { SFA }\end{array}$ \\
\hline Mean & 0.8961 & 0.9413 & 0.8224 & $-4.52 \%$ & $-11.89 \%$ & - & $7,37 \%$ \\
Std. Dev. & 0.1155 & 0.0957 & 0.1194 & - & - & - \\
Median & 0.9353 & 1.000 & 0.8526 & $-6.47 \%$ & $-14.74 \%$ & $8.27 \%$ \\
Min & 0.692 & 0.734 & 0.646 & $-4.2 \%$ & $-8.8 \%$ & $4.6 \%$ \\
Max & 0.999 & 1.000 & 0.994 & - & - & - \\
\hline
\end{tabular}

Source: Author. 
From Table 4, the overall analysis indicates that, on average, the PHCFs in the different health regions are technically inefficient, but with variability in the values of the estimates depending on the method used. In other words, it is possible to improve on average the use of resources allocated to PHCFs in Côte d'Ivoire and achieve the same health outcomes within the framework of public policies promoting primary health care.

Indeed, estimates reveal an average technical efficiency score of the health regions' PHCFs of $94.13 \%$ for the DEA versus $89.61 \%$ for the SFA and $82.24 \%$ for the double bootstrap DEA. These results confirm the fact that DEA scores are indeed subject to bias as shown by various studies comparing DEA results to DEA double bootstrap results (Anang et al., 2020; Olivares et al., 2020; Tiéhi, 2020; Diarrassouba, 2018; Ouertani et al, 2018; Pérez-Cárceles et al., 2018)) or those comparing the DEA to the SFA (Lawanson \& Novignon, 2017; Katharakis et al., 2014) and those comparing the DEA double bootstrap to the SFA (Lawanson \& Novignon, 2017; Katharakis et al., 2014).

Table 5. SFA, DEA, and DEA double bootstrap technical efficiency scores for PHCFs by health region

\begin{tabular}{|c|c|c|c|c|c|c|}
\hline & \multicolumn{2}{|c|}{ SFA } & DEA & \multicolumn{3}{|c|}{$\begin{array}{c}\text { DEA } \\
\text { double bootstrap }\end{array}$} \\
\hline & Scores $\hat{\theta}$ & Rank & Scores $\hat{\theta}$ & Scores & $\hat{\hat{\theta}} \quad$ (bias-corrected) & Rank \\
\hline Abidjan & 0.8939 & 12 & 1.000 & & 0.8673 & 9 \\
\hline Agneby-tiassa-me & 0.7257 & 17 & 0.7851 & & 0.8497 & 10 \\
\hline Belier & 0.9353 & 10 & 0.9291 & & 0.7075 & 14 \\
\hline Bounkani-gontougo & 0.7569 & 16 & 0.9353 & & 0.9299 & 5 \\
\hline Cavally-guemon & 0.9982 & 7 & 1.000 & & 0.6714 & 18 \\
\hline Gbeke & 0.9983 & 6 & 0.8357 & & 0.6862 & 15 \\
\hline Gbokle-nawa-san-pedro & 0.6998 & 18 & 1.000 & & 0.6780 & 17 \\
\hline Gôh & 0.7993 & 15 & 0.8027 & & 0.7944 & 11 \\
\hline Hambol & 0.9991 & 2 & 1.000 & & 0.9094 & 6 \\
\hline Haut_sassandra & 0.8328 & 13 & 1.000 & & 0.9537 & 4 \\
\hline Indenie_duablin & 0.9981 & 8 & 1.000 & & 0.7576 & 13 \\
\hline Kabadougou-bafing-folon & 0.999 & 3 & 1.000 & & 0.9941 & 1 \\
\hline Loh-djiboua & 0.8980 & 11 & 1.000 & & 0.6467 & 19 \\
\hline Marahoue & 0.8242 & 14 & 1.000 & & 0.6850 & 16 \\
\hline N'zi-ifou & 0.9790 & 9 & 0.7337 & & 0.7901 & 12 \\
\hline Poro-tchologo-bagoue & 0.9989 & 4 & 1.000 & & 0.9737 & 3 \\
\hline Sud-comoe & 0.6915 & 19 & 1.000 & & 0.8677 & 8 \\
\hline Tonkpi & 0.9987 & 5 & 1.000 & & 0.8785 & 7 \\
\hline Worodougou-bere & 0.9993 & 1 & 1.000 & & 0.9885 & 2 \\
\hline
\end{tabular}

Source. Author.

The sensitivity of the DEA score relative to the other two models (-4.52\% and $-11.89 \%)$ illustrates this trend. The mean DEA score is $4.52 \%$ higher than the mean SFA score and $11.89 \%$ higher than the mean bias-corrected score. This bias correction, through the DEA double boostrap, shows on the contrary a positive variation (7.37\%) between the mean bias-corrected score and the mean SFA score in accordance with the vast majority of studies on the subject (Lawanson \& Novignon, 2017; Katharakis et al., 2014). In other words, the mean technical SFA score $(89.61 \%)$ is higher than the bias-corrected DEA score $(82.24 \%)$ as in most of the studies comparing them. Specifically, the mean SFA score in this study is $7.37 \%$ higher than the mean bias-corrected score $(82.24 \%)$.

This variability in the technical ineffectiveness of PHCFs is even more noticeable between health regions. Table 5 shows the regional inequalities in this sensitivity of the average observed technical inefficiency of the PHCFs by the three methods. A large majority of the health regions, 79\%, followed this trend with relative stability in the ranking (the rank). As an illustration, the Worodougou-bere, Hambol and Gbokle-nawa regions move from $98.85 \%, 90.94 \%$ and $67.80 \%$ respectively for the bias-corrected scores to $99.93 \%, 99.91 \%$ and $69.98 \%$ with respective ranks from 2nd, 6th and 17th to 1st, 2nd and 18th for the SFA scores. However, this trend between SFA and DEA double bootstrap shows an opposite trend for the other $21 \%$ of health regions with very high sensitivity at the rank level. Thus, the DEA double bootstrap scores of these regions are higher than the SFA scores. The Agneby-tiassa-mé, Bounkani-gontougo, Haut_sassandra, and Sud-Comoé regions, respectively, increased from $84.97 \%, 92.99 \%, 95.37 \%$, and $86.77 \%$ for bias-corrected scores to $72.57 \%, 75.69 \%, 83.28 \%$, and 
$69.15 \%$ for SFA scores, with ranks changing from 10th, 5th, 4th, and 8th to 17th, 16th, 13th, and 19th. In addition, $42 \%$ of the regions, or eight out of 19 , had scores very nearly equal to 1 , anything that would prejudge the difficulties in correcting for possible biases related to the likely correlations between variables in the SFA combined with the difficulty in determining an adequate functional form of the production function and sensitivity to sample size (Lawanson \& Novignon, 2017; Katharakis et al., 2014).

\subsection{Determinants of Technical Inefficiency: SFA Sensitivity and DEA Post-Estimation Models}

The factors that explain the technical ineffectiveness of the PHCFs in the health regions are presented and discussed (Table 6) in relation to the overall significance of each method and the variability of these factors by method.

Table 6. Factors explaining the technical inefficiency of PHCFs

\begin{tabular}{|c|c|c|c|c|c|c|c|c|}
\hline \multirow[b]{2}{*}{ Variables } & \multicolumn{2}{|c|}{ SFA } & \multicolumn{2}{|c|}{ Tobit } & \multicolumn{2}{|c|}{ Truncated standard regression } & \multicolumn{2}{|c|}{ DEA double bootstrap } \\
\hline & Coef. & S. E & Coef. & S. E & Coef. & S. E & Coef. & SE \\
\hline $\mathrm{Nb} \_$ESPC & 0,1375 & 0,9709 & $-0,0015$ & 0,0013 & 0,001 & 0,0010 & $-0,0004$ & 0,00036 \\
\hline Taille_moy & $0,9766 * * *$ & 0,1599 & $0,1454 *$ & 0,0741 & $-0,0126$ & 0,0364 & $0,0751 * *$ & 0,0263 \\
\hline Hbt/Inf__ & $-0,0006$ & 0,0004 & $0,0001^{* *}$ & $8.94 \mathrm{e}-06$ & 0,0001 & 0,0001 & $-0,0001 * * *$ & $4.2 \mathrm{e}-06$ \\
\hline$\%$ Inf/persmed & $-0,5256 * *$ & 0,1695 & 0,0054 & 0,0147 & $-0,0092 *$ & 0,0048 & $-0,0187 * * *$ & 0,0020 \\
\hline Acc_Geo & $0,0078 * * *$ & 0,0019 & $-0,0087$ & 0,0097 & $0,0122 * *$ & 0,004 & $0,01376^{* * *}$ & 0,0038 \\
\hline Taux_Alphabet & 0,0409 & 0,0772 & $-0,0087$ & 0,00513 & $-0,0039^{*}$ & 0,0023 & $-0,0139 * * *$ & 0,001 \\
\hline Taux_Extrempa & $0,6645^{* * *}$ & 0,0903 & $-0,0055$ & 0,0124 & $-0,0019$ & 0,0102 & $0,0242 * *$ & 0,0104 \\
\hline Prob > chi 2 & \multicolumn{2}{|c|}{0.0000} & \multicolumn{2}{|c|}{0.0001} & \multicolumn{2}{|c|}{0.0125} & 0.0000 & \\
\hline
\end{tabular}

Source. Author.

For SFA: $\sigma^{2}=0,0177$ and $\gamma=0,703$

$* * *=1 \%$ significance, $* *=5 \%$ significance, $*=10 \%$ significance; $\mathrm{S} . \mathrm{E}=$ Standard deviation;

Coef. $=$ coefficient Prob $=$ probability.

It should be remembered that a positive sign of the coefficient of an explanatory variable indicates an obstacle (a positive effect on inefficiency but a negative effect on technical efficiency) while a negative sign implies an impact, a positive marginal effect on the technical efficiency of the health regions.

Overall, Table 6 indicates that all four models are significant and that there are significant explanatory factors for inefficiencies, the proportion and estimated value of which differ among the models but can be grouped into two categories: levers and brakes on the technical efficiency of PHCFs in health regions.

The analysis in Figure 1 shows, out of seven (07) factors that could explain the estimated technical inefficiency, the variability in number and value of the results obtained according to the method used.

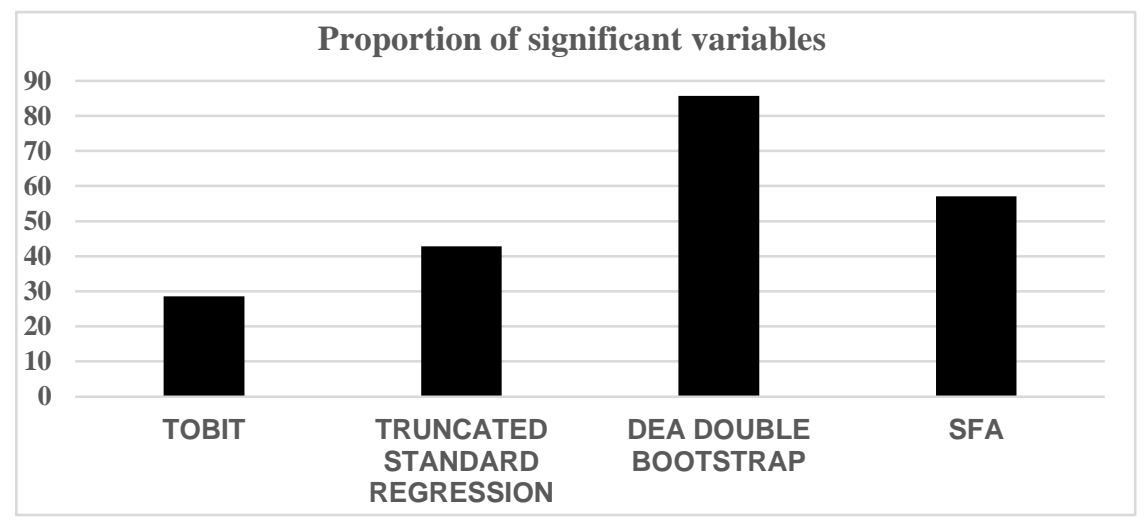

Figure 1. Comparison of the sensitivity of Tobit, Truncated Standard Regression, DEA Double Bootstrapand SFA models

Source. Author.

Figure 1 shows that the Tobit model in this study is the model with the lowest number of significant variables, accounting for 28.57 per cent of the total number of variables in the model. The truncated regression has the second lowest proportion (42.85\%), followed by the ASF with 57.14\%. The DEA double bootstrap presents the 
best proportion with $85.71 \%$ of the total number of variables that could explain the technical inefficiency of the PHCFs in the health regions in Côte d'Ivoire.

The robustness, or even the capacity of the double bootstrap DEA to provide better results than Tobit or Truncated Regression, is recognized in the vast majority of health studies comparing these different models in the search for explanatory factors of inefficiency (Diarrassouba, 2018; Pérez-Cárceles et al., 2018; Tchaumann, 2015).

In the framework of the SFA model, in addition to the significance of the global model (Prob $>$ chi2 $=0.0000$ ), the interpretation of the value of $\gamma$ is important and makes it possible to see if the production frontier is deterministic and technical inefficiency is not linked to any of the environment variables $(\gamma=1)$ or if the production frontier is stochastic and technical inefficiency can be explained by the exogenous variables (environment variables) in the model $(\gamma<1)$

$$
\gamma=\frac{\sigma^{2} u}{\sigma^{2}}=\frac{\sigma^{2} u}{\sigma^{2} u+\sigma^{2} v}
$$

Results show $\sigma_{\mathrm{u}}=0.1114653$ and $\sigma_{\mathrm{v}}=0.072487$.

In this study, $\gamma=0$, "703". This result shows that the production frontier is therefore stochastic and that there are exogenous variables that account for $70.3 \%$ of the technical inefficiency of health regions in Côte d'Ivoire. However, about $30 \%$ (29.7\%) of the technical inefficiency of the PHCFs in the health regions is related to random variables (statistical noise). In other words, almost one-third of the inefficiency can be attributed to measurement errors or other random variables. Anything that suggested inadequacies in using the SFA in health cross-sectional and small sample size data as in the present study.

This explanation is illustrated by the larger proportion of variables that could explain the technical inefficiency estimated in the DEA double bootstrap with respect to the SFA. This trend is also confirmed in the majority of studies comparing the two methods (Lawanson \& Novignon, 2017; Katharakis et al., 2014).

Regarding the influence of explanatory factors on technical inefficiency, the results show that three variables (the proportion of nurses in the medical staff, the ratio of inhabitants per nurse, and the adult literacy rate by region) are likely to increase the technical efficiency of the PHCF in health regions in Côte d'Ivoire with the DEA double bootstrap versus one variable in the SFA. On the other hand, both models (SFA and DEA double bootstrap) each have three variables that significantly and negatively affect the technical efficiency of the PHCFs in the health regions in Côte d'Ivoire (the average capacity of the PHCFs in terms of the number of observation beds, the geographic accessibility in terms of the average distance separating the populations from the nearest PHCF by region, and the rate of extreme poverty by region).

These trends in the explanatory factors in this study are consistent with most studies in this area. Indeed, the proportion of nurses in the medical staff, the ratio of inhabitants per nurse, and the adult literacy rate by region generally appear as levers of the technical efficiency of healthcare institutions (Tiéhi, 2020; Diarrasouba, 2018; Ouertani et al., 2018; Alvarez \& Hernandez, 2009).

Also, the size of the PHCFs (approximated by average capacity), geographic accessibility and the rate of extreme poverty by region appear in the vast majority of studies to hinder the technical efficiency of health facilities. Reducing their influence is presented as a source of reducing technical inefficiency (Tehi, 2020; Ouertani et al., 2018; Combier et al., 2013 and Afonso \& St. Aubyn, 2011).

\section{Conclusions}

The aim of this study was to examine to what extent the estimation of the factors explaining the technical inefficiency of basic health care provision in Côte d'Ivoire is consistent with the econometric methods used in the literature.

Using cross-sectional data, this study compared the sensitivity of the technical efficiency scores of the PHCFs in the health regions with respect to the DEA, SFA, and DEA double bootstrap methods. This sensitivity of the scores induced a corollary variability in the proportion and significance value of the coefficients of the determinants of technical inefficiency estimated through the Tobit, standard truncated regression, SFA, and DEA double bootstrap methods.

This study raised the difficulties of the SFA in producing optimal health outcomes with small cross-sectional and sample size data compared to the DEA double bootstrap, which corrected for the shortcomings of the conventional DEA. This inadequacy of the SFA would be related to the difficulty in establishing an appropriate functional form of the health production function and the small sample size. 
The results of the study showed, on average, an overall technical inefficiency in the provision of basic health care in Côte d'Ivoire regardless of the method used, with scores of $94.13 \%$ for the DEA versus $89.61 \%$ for the SFA and $82.24 \%$ for the DEA double bootstrap.

These results confirm the inadequacies and inequalities between regions in public policies for promoting primary health care in Côte d'Ivoire. This observation leads to the need to strengthen the levers capable of increasing this effectiveness and the imperative of seeking to control the obstacles likely to degrade it. In this respect, the study, in the context of improving the use of resources allocated to these institutions, showed that the proportion of nurses in the medical staff, the ratio of inhabitants per nurse and the adult literacy rate by region would be favorable factors. On the other hand, the size of the PHCFs, geographic accessibility and the rate of extreme poverty by region should be taken into account. Reducing the influence of these latter factors would improve the technical efficiency of the PHCFs in the health regions of Côte d'Ivoire.

However, the results of this study are subject to certain limitations. Among others, the small sample size certainly influenced the results of the different methods. Also, the scores obtained, and therefore also the factors explaining these scores, remain dependent on the choice of variables (inputs and outputs) even more so when the sample size remains small.

Ultimately, the choice of one method over another should take into account the specificities of the data and variables and, above all, the choice of the researcher in an operational way. This study can be used to shed some light but cannot make a scientific decision between these methods.

\section{References}

Afonso, A., \& St. Aubyn, M. (2011). Assessing health efficiency across countries with a two-stage and Bootstrap analysis. Applied Economics Letters, 18(15), 14-27. https://doi.org/10.1080/13504851.2010.541149

Aigner, D., Lovell, C. K., \& Schmidt, P. (1977). Formulation and estimation of stochastic frontier production function models. Journal of Econometrics, 6(1), 21-37.https://doi.org/10.1016/0304-4076(77)90052-5

Alvarez, J. L., Gil, R., Hernández, V., \& Gil, A. (2009). Factors associated with maternal mortality in Sub-Saharan Africa: an ecological study. BMC Public Health, (9), 462. https://doi.org/10.1186/1471-2458-9-462

Anang, B. T., Alhassan, H., \& Danso-Abbeam, G. (2020). Technology adoption and technical efficiency of smallholder farmers in Tolon district of Ghana: double bootstrap DEA approach. Agricultural Economics and Policy. https://doi.org/10.21203/rs.3.rs-17237/v1

Battese, G., \& Corra, G. (1977). Estimation of a production frontier model with application to the pastoral zone of Eastern Australia. Aust. J. Agric. Resour. Econ., 21, 167-179. https://doi.org/10.1111/j.1467-8489.1977.tb00204.x

ChafFai, M. E. (1997). Estimating input-specific technical inefficiency: The case of the Tunisian banking industry. European Journal of Operational Research, 98(2), 314-331. https://doi.org/10.1016/S0377-2217(96)00350-5

Combier, E., Charreire, H., Le Vaillant, M., Michaut, F., Ferdynus, C., Amat-Roze, J., \& Zeitlin, J. (2013). Temps d'accès aux maternités Bourguignonnes et indicateurs de santé périnatale. Journal de Gestion et d'Economies Médicales, 31(6), 348-368. https://doi.org/10.3917/jgem.136.0348.

Diarrassouba, A. S. (2018). Efficience des Etablissements Sanitaires de Premier Contact en Côte d'Ivoire, une application double bootstrap DEA. Revue Internationale de Gestion et d'Economie, 1(5), 120-143.

Dukhan, Y. (2010). Améliorer l'efficience des systèmes de santé et la protection financière contre le risque maladie dans les pays en développement (p. 282). Thèse de doctorat Centre d'Etude et de Recherche sur le développement International (CERDI), Université d'Auvergne- Clermont-Ferrand I.

Farrell, M. J. (1957). The Measurement of Productive Efficiency. Journal of the Royal Statistical Society, (120), 253-290. https://doi.org/10.2307/2343100

Jacobs, R., Smith, P., \& Street, A. (2006). Frontmatter. In Measuring Efficiency in Health Care: Analytic Techniques and Health Policy (pp. I-Iv). Cambridge: Cambridge University Press. https://doi.org/10.1017/CBO9780511617492

Katharakis, G., Katharaki, M., \& Katostaras, T. (2014). An empirical study of comparing DEA and SFA methods to measure hospital units' efficiency. International Journal of Operational Research, 21(3), 341-364. https://doi.org/10.1504/IJOR.2014.065413 
Kirigia, J. M., \& Asbu, E. Z. (2013). Technical and scale efficiency of public community hospitals in Eritrea: an exploratory study. Health Economics Review, 3(6). http://doi.org/10.1186/2191-1991-3-6.

Kochou, S. H., \& Rwenge, M. J. (2014). Facteurs sociaux de la non-utilisation des services de soins prénatals ou de leur utilisation inadéquate en Côte d'Ivoire. African Evaluation Journal, 2(1), 1-12. https://doi.org/10.4102/aej.v2i1.79

Lawanson, A. O., \& Novignon, J. (2017). Comparative Analysis of SFA and DEA Models: An Application to Health System Efficiency in SSA. Asian Journal of Humanities and Social Studies, 5(1). Retrieved from https://www.ajouronline.com/index.php/AJHSS/article/view/4373

Leleu, H., Dervaux, B. (1997). Comparaison des différentes mesures d'efficacité technique: Une application aux centres hospitaliers français. Économie \& Prévision, 3(4), 129-130. https://doi.org/10.3406/ecop.1997.5866

Meeusen, W., \& van Den Broeck, J. (1977). Efficiency estimation from Cobb-Douglas production functions with composed error. International Economic Review, 18(2), 435-444. https://doi.org/10.2307/2525757

MSLS. (2013). Rapport annuel sur la situation sanitaire (p. 104). Ministère de la santé et de la Lutte contre le sida

Mujasi, P. N., Asbu, E. Z., \& Puig-Junoy, J. (2016). How efficient are referral hospitals in Uganda? A data envelopment analysis and Tobit regression approach. BMC Health Services Research, 16(230). https://doi.org/10.1186/s12913-016-1472-9

Olivares, B. E., Sánchez, G. Y. Y., \& Núñez, R. J. E. (2020). Operational efficiency of mexican water utilities: Results of a double-bootstrap data envelopment analysis. OPENAIRE, 12(553). http://dx.doi.org/10.3390/w12020553

OMS. (2018). Couverture sanitaire universelle: Soins de santé primaires en vue de la couverture sanitaire universelle. Documents d'appui. Conférence mondiale sur les soins de santé primaires. Retrieved from https://www.who.int/primary-health/conference-phc/background-documents.

OMS. (2019). Rapport sur le suivi de la couverture sanitaire universelle (CSU). Retrieved from https://www.who.int/fr/primary-health/ septembre 2019

Ouellette, P., \& Petit, P. (2010). Mesure de l'efficience des établissements de santé: Revue et synthèse méthodologique. Centre sur la productivité et la prospérité, HEC Montréal, p. 45.

Ouertani, M. N., Naifar, N., \& Haddad, H. B. (2018). Assessing government spending efficiency and explaining inefficiency scores: DEA-bootstrap analysis in the case of Saudi Arabia. Cogent Economics \& Finance, 6(1). https://doi.org/10.1080/23322039.2018.1493666;

Pérez-Cárceles, M. C., Gómez-Gallego, J. C., \& Gómez-Gallego, M. (2018). Environmental factors affecting European and Central Asian health-systems' bias-corrected efficiency. Applied Economics, 50(32), 3432-3440. https://doi.org/10.1080/00036846.2017.1420901

Simar, L., \& Wilson, P. W. (2007). Estimation and Inference in Two-Step. Semi-Parametric Models of Production Processes. Journal of Econometrics, (136), 31-64. https://doi.org/10.1016/j.jeconom.2005.07.009

Tauchmann, H. (2015). Simarwilson: DEA based two-step efficiency analysis. In 2015 German Stata Users Group Meeting.

Tiehi, T. N. (2020). Technical Inefficiency of District Hospitals in Côte d'Ivoire: Measurement, Causes and Consequences. International Journal of Economics and Finance, 12(9), 35-45. https://doi.org/10.5539/ijef.v12n9p35

Varabyova, Y., \& Schreyögg, J. (2013). International comparisons of the technical efficiency of the hospital sector: Panel data analysis of OECD countries using parametric and non-parametric approaches. Health Policy, 112(1-2), 70-79. https://doi.org/10.1016/j.healthpol.2013.03.003

\section{Copyrights}

Copyright for this article is retained by the author(s), with first publication rights granted to the journal.

This is an open-access article distributed under the terms and conditions of the Creative Commons Attribution license (http://creativecommons.org/licenses/by/4.0/). 